\section{ABCS}

How to cite this article: Silva et al. Authorship characteristics of retracted COVID-19 articles. ABCS Health Sci. 2021;46:e021104. https://doi.org/10.7322/abcshs.2021207.1924

Corresponding author: Rafaela Carolina da Silva - Universidade do Estado de São Paulo - Avenida Hygino Muzzi Filho, 737 - Mirante - CEP: 17525-900 - Marília (SP), Brazil -

E-mail: rafaela.c.silva@unesp.br

Declaration of interest: nothing to declare

This is an open access article distributed under the terms of the Creative Commons Attribution License

(C) 2021 The authors

\title{
Authorship characteristics of retracted COVID-19 articles
}

\author{
Rafaela Carolina da Silva1, Hadiseh Heidari², Amanda Mendes da Silva ${ }^{1}$ \\ ${ }^{1}$ Programa de Ciência da Informação, Universidade do Estado de São Paulo (UNESP) - São Paulo \\ (SP), Brazil \\ ${ }^{2}$ Knowledge and Information Science, University of Qom (UQ) - Qom, Iran
}

As new variants continue to emerge and the spread of the virus continues to pervade all nations and evade efforts to contain it, it appears that COVID-19 will likely remain a long-term issue. Since the publication of new scientific research findings is crucial for the decisive fight against this disease ${ }^{1}$, researchers have published thousands of articles in a wide range of fields of knowledge to help better understand and navigate this crisis. Following the explosion of publications in this period, some of the published articles were retracted by the authors or editors of journals. Reasons such as the global rush to gain more knowledge, the rapid increase in scientific outputs, the carelessness of researchers, and the reduction in time and quality of the peer reviews led to the growth of these retracted articles ${ }^{2}$. Such articles can potentially endanger the health and evidencebased planning for those impacted by the coronavirus ${ }^{2}$. The growth and sensitive nature of retracted papers led to bibliometrics studies on them, although few $\mathrm{f}^{3,4}$, which focused more on the level of documents. Since the authors are the creators of scientific publications, examining their characteristics can complement the previous studies ${ }^{3,4}$ for a broader insight about retracted COVID-19 articles. To address the gap in our knowledge of authors of retracted articles, we reflected authorship characteristics of these articles in this paper.

We explored the retracted COVID-19 articles from the link https://retractionwatch.com/retracted-coronavirus-covid-19-papers/. Also, we searched in PubMed and Scopus on March, 1, 2021 by include keywords: "COVID-19" or "coronavirus disease 2019" or "coronavirus 2019" or "SARS-COV-2" or "2019-nCov". After removing the duplicate papers, 54 retracted COVID-19 articles remained. It is worth noting, several articles were in "Temporarily retracted", "Expressions of concern" sections ignored, same study by Soltani and Patini ${ }^{4}$. Also, according to the Retraction Watch website (www.retractionwatch.com), we made no distinction between withdrawal and retraction, because journals' system not always reflects what the papers retract, and to sometimes make a paper disappear without a trace. After identifying the papers, we evaluated the authors of papers by academic degrees, retraction background (in Retraction Watch Database and Scopus), and metrics overview from Scopus (documents by author, citations, and h-index), gender (first and last authors). We searched authors manually in Google (like the academic profile, ResearchGate, Google Scholar, and other official ways).

Table 1 displays the findings for characteristics of authors of retracted COVID-19 articles. Gender of authors of retracted COVID-19 articles is roughly equal to overall authorship of all COVID-19 articles (1): 20-46\%, depending on medical specialty, for a woman first author, with a median of $31 \%$; $13-37 \%$ for a woman last author, with a median of $29 \% .81 \%$ of authors have completed a $\mathrm{PhD}$ or MD program. Most authors 
Table 1: The characteristics of authors of COVID-19 retracted articles

\begin{tabular}{|c|c|c|c|}
\hline \multirow{4}{*}{ Gender } & \multirow{2}{*}{ First authors } & Male & $73 \%$ \\
\hline & & Female & $27 \%$ \\
\hline & \multirow{2}{*}{ Last authors } & Male & $72 \%$ \\
\hline & & Female & $28 \%$ \\
\hline \multirow{8}{*}{ Job Role } & \multicolumn{2}{|c|}{ MD } & $32 \%$ \\
\hline & \multicolumn{2}{|c|}{ Professor } & $25 \%$ \\
\hline & \multicolumn{2}{|c|}{ PhD Candidate } & $25 \%$ \\
\hline & \multicolumn{2}{|c|}{ MS Student } & $9 \%$ \\
\hline & \multicolumn{2}{|c|}{ Post-Doctoral Fellow } & $3 \%$ \\
\hline & \multicolumn{2}{|c|}{ College student } & $2 \%$ \\
\hline & \multicolumn{2}{|c|}{ MD Student } & $2 \%$ \\
\hline & \multicolumn{2}{|c|}{ Program Director } & $2 \%$ \\
\hline \multirow{2}{*}{$\begin{array}{l}\text { Previously } \\
\text { Retracted Paper? }\end{array}$} & \multicolumn{2}{|c|}{ Yes } & $33 \%$ \\
\hline & \multicolumn{2}{|c|}{ No } & $67 \%$ \\
\hline \multirow{4}{*}{$\begin{array}{l}\text { Authors per } \\
\text { documents }\end{array}$} & \multicolumn{2}{|c|}{ Mean } & 6 \\
\hline & \multicolumn{2}{|c|}{ Median } & 5.5 \\
\hline & \multicolumn{2}{|c|}{ Minimum } & 1 \\
\hline & \multicolumn{2}{|c|}{ Maximum } & 24 \\
\hline \multirow{4}{*}{$\begin{array}{l}\text { Number of } \\
\text { documents by } \\
\text { author }\end{array}$} & \multicolumn{2}{|c|}{ Mean } & 61 \\
\hline & \multicolumn{2}{|c|}{ Median } & 17 \\
\hline & \multicolumn{2}{|c|}{ Minimum } & 1 \\
\hline & \multicolumn{2}{|c|}{ Maximum } & 518 \\
\hline \multirow{4}{*}{ Citations } & \multicolumn{2}{|c|}{ Mean } & 3159 \\
\hline & \multicolumn{2}{|c|}{ Median } & 232 \\
\hline & \multicolumn{2}{|c|}{ Minimum } & 0 \\
\hline & \multicolumn{2}{|c|}{ Maximum } & 70422 \\
\hline \multirow{4}{*}{ H-index } & \multicolumn{2}{|c|}{ Mean } & 12 \\
\hline & $\mathrm{Me}$ & & 6 \\
\hline & Mini & & 0 \\
\hline & Maxi & & 80 \\
\hline
\end{tabular}

(based on median figures) are moderately accomplished, with a couple of dozen documents published in their career, a few hundred citations, and an h-index of 8 . Retracted articles averaged 5 and 6 authors each, which is similar to the average number of authors on all articles published in medical journals over the past five decades.

The results show that all demographics appear normal. However, there is concern about the background of researchers in the production of retreat articles because in this small community $(n=59)$ about $20 \%$ of them have other retreat articles in their CV. The retracted COVID-19 papers have a similar number of authors to the traditional medical article, such that there should be plenty of minds and eyes looking over the paper and mitigating the likelihood that a retraction would need to occur (though this is clearly not the case). However, the number of authors of retracted COVID-19 articles in this study is higher than the number of authors of COVID-19 articles ${ }^{5}$, which shows that increasing the size of authorship team does not necessarily reduce the probability of retraction of articles. Continued research about retracted COVID-19 articles can continue to help prevent the further dissemination of questionable research findings.

\section{ACKNOWLEDGEMENTS}

We are grateful to Amrollah Shamsi and Brady Lund for supporting this survey.

\section{REFERENCES}

1. Song P, Karako T. COVID-19: Real-time dissemination of scientific information to fight a public health emergency of international concern. Biosci Trends. 2020;14(1):1-2. https://doi.org/10.5582/bst.2020.01056

2. Mansourzadeh MJ, Shamsi A. Concerns About Research Ethics in COVID-19 Publications. Asia Pac J Public Health. 2020;32(8):503-4. https://doi.org/10.1177/1010539520956439

3. Cortegiani A, Catalisano G, Ippolito M, Giarratano A, Absalom AR, Einav S. Retracted papers on SARS-CoV-2 and COVID-19. Br J
Anaesth. 2021;126(4):e155-6.

https://doi.org/10.1016/j.bja.2021.01.008

4. Soltani P, Patini R. Retracted COVID-19 articles: a side-effect of the hot race to publication. Scientometrics. 2020;1-4. https://doi.org/10.1007/s11192-020-03661-9

5. Homolak J, Kodvanj I, Virag D. Preliminary analysis of COVID-19 academic information patterns: a call for open science in the times of closed borders. Scientometrics. 2020;124:2687-2701. https://doi.org/10.1007/s11192-020-03587-2 